\title{
Non-cell autonomous mechanisms control mitochondrial gene dysregulation in polycystic ovary syndrome
}

\author{
Alba Moreno-Asso ${ }^{1,2}$, Ali Altıntaş ${ }^{[3}{ }^{3}$, Luke C Mcllvenna1, Rhiannon K Patten ${ }^{1}$, Javier Botella1 ${ }^{1}$, Andrew J McAinch ${ }^{1,2}$, \\ Raymond J Rodgers ${ }^{1,4}$, Romain Barrès ${ }^{3}$ and Nigel K Stepto ${ }^{D 1,2}$
}

${ }^{1}$ Institute for Health and Sport (iHeS), Victoria University, Melbourne, Australia

${ }^{2}$ Australian Institute for Musculoskeletal Science (AIMSS), Victoria University, Melbourne, Australia

${ }^{3}$ Novo Nordisk Foundation Centre for Basic Metabolic Research, Faculty of Health and Medical Sciences, University of Copenhagen,

Copenhagen, Denmark

4Discipline of Obstetrics and Gynaecology, School of Medicine, Robinson Research Institute, The University of Adelaide, Adelaide, South

Australia, Australia

Correspondence should be addressed to A Moreno-Asso or R Barrès: alba.moreno@vu.edu.au or barres@sund.ku.dk

\begin{abstract}
Polycystic ovary syndrome (PCOS) is a common endocrine disorder associated with insulin resistance and impaired energy metabolism in skeletal muscle, the aetiology of which is currently unclear. Here, we mapped the gene expression profile of skeletal muscle from women with PCOS and determined if cultured primary myotubes retain the gene expression signature of PCOS in vivo. Transcriptomic analysis of vastus lateralis biopsies collected from PCOS women showed lower expression of genes associated with mitochondrial function, while the expression of genes associated with the extracellular matrix was higher compared to controls. Altered skeletal muscle mRNA expression of mitochondrial-associated genes in PCOS was associated with lower protein expression of mitochondrial complex II-V, but not complex I, with no difference in mitochondrial DNA content. Transcriptomic analysis of primary myotube cultures established from biopsies did not display any differentially expressed genes between controls and PCOS. Comparison of gene expression profiles in skeletal muscle biopsies and primary myotube cultures showed lower expression of mitochondrial and energy metabolism-related genes in vitro, irrespective of the group. Together, our results show that the altered mitochondrial-associated gene expression in skeletal muscle in PCOS is not preserved in cultured myotubes, indicating that the in vivo extracellular milieu, rather than genetic or epigenetic factors, may drive this alteration. Dysregulation of mitochondrial-associated genes in skeletal muscle by extracellular factors may contribute to the impaired energy metabolism associated with PCOS.
\end{abstract}

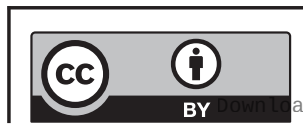

This work is licensed under a Creative Commons Attribution 4.0 International License.
Journal of Molecular Endocrinology (2021) 68, 63-76 


\section{Introduction}

Polycystic ovary syndrome (PCOS) is the most common endocrine disorder in reproductive-aged women, affecting their metabolic, reproductive and mental health (Ehrmann 2005, Teede et al. 2010). The clinical hallmarks of PCOS include hyperandrogenism, ovulatory dysfunction and polycystic ovaries (Rotterdam ESHRE/ ASRM-Sponsored PCOS Consensus Workshop Group 2004). At the pathophysiological level, PCOS has a strong metabolic component with insulin resistance being present in 38-95\% of women with PCOS (Moghetti et al. 2013, Stepto et al. 2013, Tosi et al. 2017). Individuals with PCOS can present with a $25 \%$ reduction in insulin sensitivity, independent of, but exacerbated by, obesity, when measured by euglycaemic-hyperinsulinaemic clamp (Cassar et al. 2016). Insulin resistance and compensatory hyperinsulinaemia are considered primary drivers of PCOS pathophysiology, contributing to hyperandrogenism and reproductive dysfunction (Dunaif et al. 1989, Teede et al. 2010). Insulin resistance in PCOS has been suggested to be mechanistically distinct from that of other metabolic disorders (Dunaif et al. 1989, Corbould 2008). However, there is a lack of understanding about the molecular mechanisms leading to insulin resistance in metabolic tissues (Stepto et al. 2019).

Skeletal muscle is a major contributor to insulin resistance accounting for $85 \%$ of post-prandial wholebody glucose disposal (DeFronzo et al. 1981). Numerous studies have attempted to elucidate the mechanisms involved in the development of skeletal muscle insulin resistance in PCOS, yet, the picture is unclear. Some evidence points towards downstream insulin signalling defects as causal factors leading to skeletal muscle insulin resistance, which occurs independently of obesity and which are distinct from those observed in type 2 diabetes (Dunaif et al. 1992, 2001, Corbould 2008, Højlund et al. 2008). Conversely, other studies have not been able to attribute any insulin signalling defects or decreased expression of genes of the insulin signalling pathway (Skov et al. 2007, Ciaraldi et al. 2009, Hansen et al. 2019, Stepto et al. 2020). Transcriptional investigations in skeletal muscle of insulin-resistant women with PCOS identified an association between insulin resistance and decreased mitochondrial oxidative phosphorylation (OXPHOS) transcripts (Skov et al. 2007), while other studies did not find such an association (Hutchison et al. 2012, Nilsson et al. 2018). Neither mitochondrial content markers, nor respiratory function, have been reported to differ between lean and overweight/obese insulin-resistant PCOS women compared to BMI-matched controls (Rabøl et al. 2011, Hutchison et al. 2012, Konopka et al. 2015). Thus, the contribution of mitochondrial dysfunction in insulin resistance in PCOS is unclear.

Primary myotube cultures allow to distinguish between cell-autonomous defects and adaptive mechanisms as a result of the influence of extracellular factors in vivo. A previous study showed that some of the insulin signalling defects observed in vivo are conserved in myotubes from insulin-resistant PCOS women when compared with controls, but this was not accompanied by a decrease in insulin sensitivity (Corbould etal. 2005). Conversely, several studies did not detect alterations in the insulin signalling pathway in myotubes from PCOS women (Ciaraldi et al. 2009, Eriksen et al. 2010). In contrast, the metabolic phenotype and signalling defects are more unanimously preserved in myotube cultures established from donors with type 2 diabetes (Gaster et al. 2002, Thingholm et al. 2011, Gaster 2019). The conflicting studies between PCOS and type 2 diabetes support the existence of distinct aetiological mechanisms of insulin resistance in these diseases.

The present study sought to gain further insight into the mechanisms leading to metabolic dysfunction in skeletal muscle in PCOS and to determine whether cellautonomous factors are responsible for the dysregulation of skeletal muscle function in PCOS. Specifically, we investigated the transcriptomic profile of skeletal muscle and primary myotube cultures established from vastus lateralis biopsies from insulin-resistant women with PCOS compared to healthy controls. We hypothesized that skeletal muscle from women with PCOS would present with transcriptomic alterations and these would be mostly retained in primary myotube cultures.

\section{Materials and methods}

\section{Study participants}

In this study, eight overweight or obese insulin-resistant women with PCOS and seven lean healthy women were included. PCOS was diagnosed using the Rotterdam criteria, which requires any two of the following: (i) oligo- or anovulation; (ii) clinical and/or biochemical hyperandrogenism; (iii) polycystic ovaries on ultrasound and (iv) exclusion of other causes of hyperandrogenism or ovulatory dysfunction (Rotterdam ESHRE/ASRMSponsored PCOS Consensus Workshop Group 2004). Women with PCOS had their diagnosis confirmed by an endocrinologist. The healthy control group consisted of women without any features of PCOS. All women were premenopausal and aged between 18 and 40 years old.

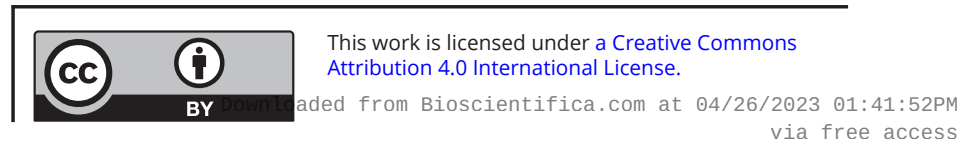


The exclusion criteria included menopause, pregnancy, smoking, type 1 or type 2 diabetes, uncontrolled hypertension (>160/100 mmHg), cardiovascular disease, renal impairment and malignancy and use of medications that interfere with endpoints (e.g. oral contraception, insulin sensitisers, anti-androgens, progestins, antihypertensives and lipid-lowering agents). Ethical approval was obtained from the Victoria University Human Research Ethics Committee (HRE17-232), and all participants provided written informed consent prior to participation in the study, as part of larger clinical trials (ACTRN12618000155291 and ACTRN12615000242527).

\section{Clinical and biochemical measures}

All clinical measures were conducted after an overnight fast and in the early follicular phase of the menstrual cycle (days 1-7) for those participants with menstrual cycles. Participant's body composition was assessed by dual energy X-ray absorptiometry (DXA) scan (iDXA GE Lunar Prodigy scanner) and performed by a licenced operator. A standard scanning protocol was used to ensure measurement reliability (Nana et al. 2015). BMI was calculated using height and weight measurements. Euglycaemic-hyperinsulinaemic clamps were performed to assess insulin sensitivity levels (DeFronzo et al. 1979). Insulin (NovoNordisk ActRapid) was infused at a constant rate $\left(40 \mathrm{mU} / \mathrm{min} / \mathrm{m}^{2}\right)$ for approximately $120 \mathrm{~min}$, with glucose infused at a variable rate to maintain a blood glucose level of $5 \mathrm{mmol} / \mathrm{L}$. Blood glucose was assessed every 5 min using a glucose analyser (YSI 2300 STAT Plus). Glucose infusion rate (GIR) was calculated during steady state, defined as the last $30 \mathrm{~min}$ of the insulinstimulated period and expressed as glucose $(\mathrm{mg}) / \mathrm{lean}$ body mass $(\mathrm{kg}) /$ minute. Blood samples were collected during the fasted state from the antecubital vein. Plasma and serum were collected in appropriate blood tubes by centrifugation and stored at $-80^{\circ} \mathrm{C}$ until samples were later batch-analysed. Plasma insulin levels were determined via radio-immuno assay kit from Millipore (Human Insulin-Specific RIA, HI-14K, Millipore), and serum antiMüllerian hormone concentration was determined by ELISA (Ultra-Sensitive AMH/MIS ELISA, AL-105, Ansh Labs) at Victoria University. Total cholesterol, triglycerides, HDL-C, LDL-C, glycosylated haemoglobin (HbA1c), sex hormone binding globulin (SHBG), dihydrotestosterone, oestradiol (E2), androstenedione and testosterone were analysed in the accredited pathology laboratory at Monash Health, Melbourne, Australia, using standard protocols as previously described (Hiam et al. 2019).

\section{Collection of muscle biopsies and establishment of primary myotube cultures}

Muscle biopsy samples from vastus lateralis were obtained from all participants following the modified Bergström technique (Bergstrom 1975, Shanely et al. 2014). Primary myotube cultures were successfully established using approximately $50 \mathrm{mg}$ of muscle biopsy sample and following the method described previously (Agley et al. 2013). Isolated myoblasts were cultured in growth media (minimum essential medium alpha $(\alpha-\mathrm{MEM})$ with $10 \% \mathrm{v} / \mathrm{v}$ fetal bovine serum, $0.5 \% \mathrm{v} / \mathrm{v}$ penicillin-streptomycin and $0.5 \% \mathrm{v} / \mathrm{v}$ amphotericin B) until reaching $80 \%$ confluence. Cells were differentiated for 6 days in differentiation media ( $\alpha$-MEM with $2 \% \mathrm{v} / \mathrm{v}$ horse serum, $0.5 \% \mathrm{v} / \mathrm{v}$ penicillinstreptomycin and $0.5 \% \mathrm{v} / \mathrm{v}$ amphotericin $\mathrm{B}$ ) until mature myotubes were formed.

\section{Measurement of glucose uptake in primary myotubes}

Insulin-stimulated glucose uptake was performed using a radioactivity-based assay $\left[{ }^{3} \mathrm{H}\right] 2$-deoxy-D-glucose ([3H]2-DG) (Chanon et al. 2017). After an overnight incubation $(16 \mathrm{~h})$ in serum-free medium, differentiated myotubes were washed three times and pre-incubated with Kreb's buffer (10 mM HEPES, $2.5 \mathrm{mM} \mathrm{NaH}_{2} \mathrm{PO}_{4}, 150$ $\mathrm{mM} \mathrm{NaCl}, 5 \mathrm{mM} \mathrm{KCl}, 1.2 \mathrm{mM} \mathrm{CaCl} 2,1.2 \mathrm{mM} \mathrm{MgSO}_{4}$, $0.1 \% \mathrm{BSA}$ ) with or without $100 \mathrm{nM}$ of insulin for $30 \mathrm{~min}$ at $37^{\circ} \mathrm{C}$. A control condition with cytochalasin $\mathrm{B}$ was also included. Then, $10 \mu \mathrm{M}$ 2-deoxy-D-glucose (2-DG) at $1 \mu \mathrm{Ci} /$ $\mathrm{mL} /$ well $\left(\left[{ }^{3} \mathrm{H}\right] 2-\mathrm{DG}\right)$ was added for exactly $15 \mathrm{~min}$. Cells were then rinsed three times with cold PBS and lysed in $500 \mu \mathrm{L}$ of $0.1 \mathrm{M} \mathrm{NaOH}$. Four hundred microlitres of each lysate was transferred to scintillation vial while $100 \mu \mathrm{L}$ was retained for quantification of total protein. Glucose uptake was determined using liquid scintillation counting on $\beta$-spectrometer (Perkin-Elmer). The unit of measurement was calculated in picomoles of $\left[{ }^{3} \mathrm{H}\right] 2-\mathrm{DG}$ taken up per minute per milligram was normalised to total protein.

\section{Determination of mitochondrial DNA copy number}

Total DNA was extracted from skeletal muscle and myotubes using the Qiagen AllPrep DNA/RNA/miRNA universal kit (Qiagen). Mitochondrial DNA (mtDNA) copy number was determined in quadruplicates using multiplex quantitative PCR. This method allows for simultaneous amplification of a mitochondrial (ND1) and a nuclear (RNAseP) gene to verify the relative abundance of mtDNA

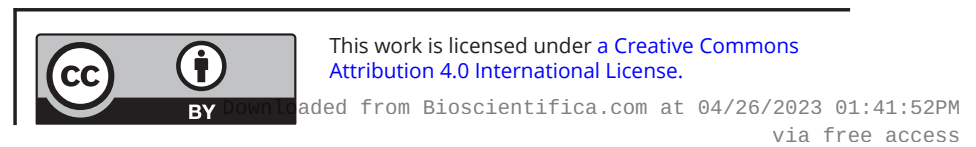


over nuclear DNA (ncDNA) (Krishnan et al. 2007). RNAseP was assessed by using the RNAseP assay kit (Thermo Fisher Scientific), and the primer and probe sequences to amplify ND1 (IDT) are as follows: forward primer (300 nM), 5'CCCTAAAACCCGCCACATCT3'; reverse primer (300 nM): 5'GAGCGATGGTGAGAGCTAAGGT3'; and probe (100 nM): 5'FAMCCATCACCCTCTACATCACCGCCC-TAMRA3'. Taqman Universal Mastermix (Thermo Fisher Scientific) was used and the assay was run on a QuantStudio ${ }^{\text {Tm }} 7$ Flex Real-Time PCR System (Applied Biosystems). The average coefficient of variation for both mtDNA and ncDNA threshold cycles (Cts) was $1.1 \%$. Data were manually curated and in the case of a S.D. of more than 0.3 for the Cts of the quadruplicates, the outlier value was suppressed from the analysis. Results were expressed as relative mtDNA/ncDNA ratio calculated by the $\Delta \Delta \mathrm{Ct}$ method using the mean of the muscle from healthy controls as reference sample (Quiros et al. 2017).

\section{RNA sequencing}

Total RNA was extracted from skeletal muscle biopsies of eight women with PCOS and six healthy women, and from primary myotubes from five women with PCOS and six healthy women using the Qiagen AllPrep DNA/RNA/ miRNA universal kit (Qiagen). Agilent RNA 600 Nano kit and Bioanalyzer instrument (Agilent Technologies) was used to assess the quality of the total RNA samples (500 ng). Sequencing libraries were prepared according to the TruSeq stranded total RNA with the Ribo-Zero Gold protocol (Illumina), as previously described (Hiam et al. 2019). Quantification of libraries was performed using the Qubit dsDNA HS assay kit (Invitrogen) to ensure optimum cluster densities. Quality control for base pair size and purity was assessed using an Agilent high-sensitivity DNA chip and Bioanalyzer instrument (Agilent Technologies). Each library was diluted to $1 \mathrm{nM}$ before being pooled and sequenced on the NovaSeq6000 (Illumina).

\section{Bioinformatic analysis of RNA sequencing data}

Sequencing reads $(n \approx 35.3 \mathrm{M})$ from FASTQ files were aligned using STAR (v2.7.2b) aligner with Ensembl human annotation (GRCh38, release 98), and gene features were counted using featureCounts from subread (v1.6.2) package resulting in $26.5 \mathrm{M}$ and $22 \mathrm{M}$ reads on average, respectively (Supplementary Fig. 1, see section on supplementary materials given at the end of this article). One library (sample: C_M_pre_2) was excluded from downstream analysis due to low read number $(n=17,549)$. The lowly expressed genes were discarded from downstream analysis using filterByExpr function from edgeR package (v3.28.1) resulting in 17,689 genes. To calculate the differentially expressed genes, a generalized linear model was fit by edgeR's (v3.32.1) voomLmFit function while blocking for participants. Genes with false discovery rate (FDR) $<0.05$ were considered as differentially expressed. Multidimensional scaling (MDS) plots were created by using batch (participants)-corrected logCPM values. All sequencing data are available under Gene Expression Omnibus data repository.

\section{Pathway enrichment analysis}

Pathway enrichment analysis was performed using the gene set enrichment analysis (GSEA) and over-representation analysis (ORA) methods as indicated. Both GSEA and ORA were performed by using clusterProfiler (v3.14.3) and Reactome database (ReactomePA R package, v1.30.10). The $\log _{2}$-fold-changes $(\log \mathrm{FC}$ ) calculated during the differential expression analysis were ranked and permuted 1 million times for GSEA. The ontologies with less than 10 and more than 500 genes were discarded. Remaining ontologies with $q$-value $<0.05$ were considered as enriched.

\section{Cluster analysis of expression patterns}

Batch (participant)-corrected gene expression values, logCPMs, were used for clustering analysis for each experimental group, which are defined as a combination of cell type (myotube, muscle) and disease (control, PCOS). The clustering analysis was performed using 'clust' algorithm (Abu-Jamous \& Kelly 2018), which resulted in 10 distinct clusters. Gene enrichment analysis using Reactome database and ORA method was performed for each cluster with the same parameters mentioned above.

\section{Quantitative reverse transcriptase PCR}

Extracted mRNA of skeletal muscle and myotube samples from eight women with PCOS and six healthy women were reverse transcribed using Bio-Rad iScript ${ }^{\mathrm{Tm}}$ RT Supermix (Bio-Rad Laboratories) and a Thermocycler (Bio-Rad Laboratories). Quantitative reverse transcriptase PCR (qRT-PCR) reactions were performed in triplicate using SsoAdvanced Universal SYBR Green Supermix (Bio-Rad Laboratories) and amplified by QuantStudio ${ }^{\mathrm{Tm}} 7$ Flex RealTime PCR System (Applied Biosystems). Specific pairs of qRT-PCR primers for nine selected genes were used (Table $1)$. Gene expression results were represented as $2-\Delta \mathrm{Ct}$ normalised to the geometric mean of the three most stable

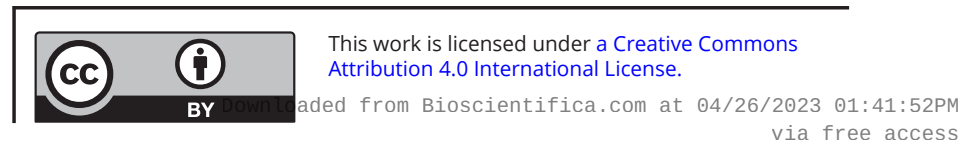


Table 1 qRT-PCR primer sequences.

\begin{tabular}{|c|c|c|}
\hline Gene symbol & Primer sequence 5'- 3' & Accession number \\
\hline RPL39 & $\begin{array}{l}\text { F: TGTTCTTGACTCCGCTGCTC } \\
\text { R: TCTCCTTTTGGAGTTGTACCTGA }\end{array}$ & NM_001000.4 \\
\hline MYL6B & $\begin{array}{l}\text { F: AACCCCAAGAGTGATGAGCTG } \\
\text { R: CACACGAAACCCCTCCAAGT }\end{array}$ & NM_001199629.2 \\
\hline PRKAG3 & $\begin{array}{l}\text { F: AGTCCTCAATCCCAAGCCAC } \\
\text { R: AGGGCTGAAGAAGCCTGAATC }\end{array}$ & NM_017431.3 \\
\hline$L P L$ & $\begin{array}{l}\text { F: GATCCATGGCTGGACGGTAA } \\
\text { R: GACAGCCAGTCCACCACAAT }\end{array}$ & NM_000237.2 \\
\hline NDUFA9 & $\begin{array}{l}\text { F: CGCATGGGGTCACAGGTAAT } \\
\text { R: CTCGCGTCCCATTCCAGAAA }\end{array}$ & NM_005002.5 \\
\hline$S D H B$ & $\begin{array}{l}\text { F: AAATGTGGCCCCATGGTATTG } \\
\text { R: AGAGCCACAGATGCCTTCTCTG }\end{array}$ & NM_003000.3 \\
\hline UQCRC2 & $\begin{array}{l}\text { F: GCAGTGACCGTGTGTCAGAA } \\
\text { R: AGGGAATAAAATCTCGAGAAAGAGC }\end{array}$ & NM_003366.4 \\
\hline COX4A1 & $\begin{array}{l}\text { F: GAGCAATTTCCACCTCTGC } \\
\text { R: CAGGAGGCCTTCTCCTTCTC }\end{array}$ & NM_001861.6 \\
\hline ATP5PD & $\begin{array}{l}\text { F: CCTCACCTCCAGGTTGGC } \\
\text { R: GCACAAGATTTCACCTTCTTCTCA }\end{array}$ & NM_001003785.2 \\
\hline MRPS7 & $\begin{array}{l}\text { F: GCAGCTTCCAGGGCTAACT } \\
\text { R: CCTCCACTGGCTTGCGATA }\end{array}$ & NM_015971.4 \\
\hline MRPL41 & $\begin{array}{l}\text { F: GACCGAATGAGCAAGTGGAC } \\
\text { R: CTCCTTGATCTGCACGAACCT }\end{array}$ & NM_032477.3 \\
\hline ACTB & $\begin{array}{l}\text { F: GAGCACAGAGCCTCGCCTTT } \\
\text { R: TCATCATCCATGGTGAGCTGGC }\end{array}$ & NM_001101.3 \\
\hline PPIA & $\begin{array}{l}\text { F: GTCAACCCCACCGTGTTCTTC } \\
\text { R: TTTCTGCTGTCTTTGGGACCTTG }\end{array}$ & NM_021130.4 \\
\hline$B 2 M$ & $\begin{array}{l}\text { F: TGCTGTCTCCATGTTTGATGTATCT } \\
\text { R: TCTCTGCTCCCCACCTCTAAGT }\end{array}$ & NM_004048.2 \\
\hline GAPDH & $\begin{array}{l}\text { F: AATCCCATCACCATCTTCCA } \\
\text { R: TGGACTCCACGACGTACTCA }\end{array}$ & NM_001289746.1 \\
\hline TBP & $\begin{array}{l}\text { F: CAGTGACCCAGCAGCATCACT } \\
\text { R: AGGCCAAGCCCTGAGCGTAA }\end{array}$ & NM_003194.4 \\
\hline
\end{tabular}

F, forward primer; R, reverse primer.

housekeeping genes (PPIA (Cyclophilin), B2M, TBP) out of five analysed (TBP, ACTB, Cyclophilin, B2M, GAPDH), selected using RefFinder (https://www.heartcure.com.au/ reffinder/).

\section{Protein immunoblotting}

Protein content was detected by Western blot using skeletal muscle samples from eight women with PCOS and six healthy controls, and six myotube cultures from women with PCOS and six from healthy controls (Supplementary Fig. 2 and Supplementary document 1). For each protein of interest, a signal linearity test was conducted to determine the ideal loading amount. Muscle lysates were diluted in $4 \times$ Laemmli buffer (0.25 M Tris, 4\% SDS, 20\% glycerol, $0.015 \%$ bromophenol blue and 10\% 2-mercaptoethanol) and were then loaded in equal amounts (10-20 $\mu \mathrm{g})$ on a Criterion $^{\text {Tm }} 4-20 \%$ TGX Stain-Free ${ }^{\mathrm{T} m}$ Precast Gels (Bio-Rad Laboratories). Samples were then separated by electrophoresis for $1.5-2.5 \mathrm{~h}$ at $100 \mathrm{~V}$ before wet transferral onto low-fluorescence PVDF membranes using a Turbo Transfer system (Bio-Rad Laboratories). Membranes were blocked at room temperature for $1 \mathrm{~h}$ using 3\% skim milk in Tris buffer saline (TBS) $0.1 \%$ tween-20 (TBS-T). After $3 \times 5$-min washes in TBS-T, membranes were incubated overnight at $4{ }^{\circ} \mathrm{C}$ with gentle agitation in primary antibody solutions (1:1000 antibody in 3\% BSA, plus 0.02\% sodium azide). The following antibodies from Abcam were used: UQCRC2 (ab14745), COX IV (ab14744), SDHA (ab14715), NDUFA9 (ab14713), ATP5A (ab14748), MRPS7 (ab138088) and MRPL41 (ab121821). Membranes were next washed $3 \times 5$ min in TBS-T and subsequently incubated under gentle agitation at room temperature with the appropriate host species-specific secondary antibody for $90 \mathrm{~min}$ in 3\% skim milk in TBS-T. Membranes were washed again for $3 \times 5$-min in TBS-T before being immersed under gentle agitation at room temperature in Clarity ECL detection substrate (Bio-rad Laboratories) or SuperSignal West Femto (ThermoFisher Scientific). Protein bands were visualised using a Bio-Rad ChemiDoc imaging system, and

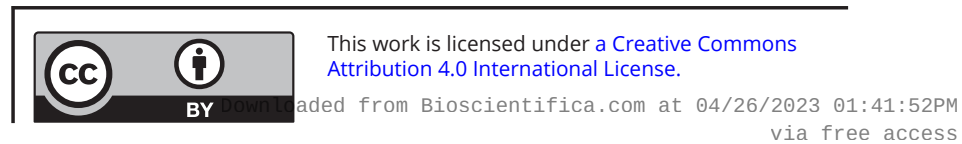


Table 2 Clinical characteristics.

\begin{tabular}{l}
\hline \\
\hline Age \\
Body composition \\
Weight $(\mathrm{kg})$ \\
BMI $\left(\mathrm{kg} / \mathrm{m}^{2}\right)$ \\
Body fat (\%) \\
Lean mass (\%) \\
Glucose homeostasis \\
HbA1c (\%) \\
Fasting insulin ( $\mu \mathrm{IU} / \mathrm{mL})$ \\
Fasting glucose (mmol/L) \\
Insulin sensitivity \\
GIR (mg/lbm kg/min) \\
Hormonal status \\
Total testosterone (nmol/L) \\
Free testosterone (pmol/L) \\
SHBG (nmol/L) \\
Dihydrotestosterone (nmol/L) \\
Androstenedione (nmol/L) \\
Estradiol (pmol/L) \\
Anti-Müllerian hormone (pmol/L) \\
Lipids \\
Cholesterol (mmol/L) \\
Triglycerides (mmol/L) \\
High-density lipoprotein (mmol/L) \\
Low-density lipoprotein (mmol/L) \\
LDL:HDL ratio \\
\hline
\end{tabular}

\begin{tabular}{c}
\hline Controls $(n=7)$ \\
\hline $25.7 \pm 5.7$ \\
$64.5 \pm 12.9$ \\
$22.2 \pm 2.6$ \\
$29.3 \pm 4.7$ \\
$70.6 \pm 8.4$ \\
$5.13 \pm 0.15$ \\
$9.98 \pm 2.44$ \\
$4.44 \pm 0.34$ \\
$16.36 \pm 4.76$ \\
\\
$0.92 \pm 0.31$ \\
$13.54 \pm 5.99$ \\
$54.01 \pm 24.51$ \\
$0.33 \pm 0.18$ \\
$3.23 \pm 0.85$ \\
$179.96 \pm 186.40$ \\
$76.73 \pm 40.30$ \\
$3.87 \pm 0.67$ \\
$0.64 \pm 0.09$ \\
$1.57 \pm 0.36$ \\
$2.02 \pm 0.57$ \\
$1.39 \pm 0.54$
\end{tabular}

\begin{tabular}{c}
\hline PCOS $(n=8)$ \\
\hline $28.3 \pm 2.5$ \\
$97.8 \pm 13.3^{\mathrm{a}}$ \\
$35.7 \pm 5.7^{\mathrm{a}}$ \\
$49.2 \pm 5.4^{\mathrm{a}}$ \\
$48.4 \pm 4.9^{\mathrm{a}}$ \\
$5.16 \pm 0.04$ \\
$14.64 \pm 6.30$ \\
$5.01 \pm 0.29 \mathrm{~b}$ \\
$7.23 \pm 3.34^{\mathrm{a}}$ \\
$1.61 \pm 0.65^{\mathrm{b}}$ \\
$37.07 \pm 13.98^{\mathrm{b}}$ \\
$26.71 \pm 10.76^{\mathrm{b}}$ \\
$0.32 \pm 0.13$ \\
$4.83 \pm 1.17^{\mathrm{b}}$ \\
$178.73 \pm 115.28$ \\
$74.11 \pm 28.09$ \\
$4.70 \pm 0.80$ \\
$1.04 \pm 0.42$ \\
$1.34 \pm 0.25$ \\
$2.90 \pm 0.68^{\mathrm{b}}$ \\
$2.21 \pm 0.51^{\mathrm{b}}$
\end{tabular}

Data presented as mean \pm S.D.

a $P<0.001$ vs controls. $b P<0.05$ vs controls.

band densities were determined using Bio-Rad ImageLab software (Bio-Rad Laboratories).

\section{Statistical analysis}

Clinical characteristics of groups were compared with two-tailed unpaired Student's t-test. Statistical analyses for glucose uptake, gene expression, protein abundance and mtDNA copy number were performed by two-way repeated measures of ANOVA with Bonferroni adjustment for multiple comparisons using GraphPad Prism software version 8.2.1 (GraphPad Software Inc.). The distributions of the data were tested using Shapiro-Wilk test; when data were not normally distributed, normality was achieved by $\log$ transformation. All data are reported as mean \pm S.D., and statistical significance was declared when $P_{\text {adj }}<0.05$.

\section{Results}

\section{Endocrine and metabolic characteristics of the subjects}

Women with PCOS were overweight with increased BMI, fat mass percentage and reduced lean mass percentage

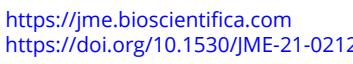

C 2021 The authors Published by Bioscientifica Ltd. Printed in Great Britain compared to healthy controls $(P<0.001)$ (Table 2). Women with PCOS also had significantly lower levels of SHBG, higher levels of total and free testosterone, androstenedione, low-density lipoprotein, LDL:HDL ratio, and fasting glucose than healthy control women $(P<0.05)$ (Table 2). GIR in women with PCOS was $49.5 \%$ lower than controls $(P<0.001)$ as measured by euglycaemichyperinsulinaemic clamp (Table 2). These clinical characteristics are in line with the previously reported phenotypical differences observed in insulin-resistant women with PCOS when compared to controls (Skov et al. 2007, Stepto et al. 2013).

\section{Altered muscle expression of genes controlling mitochondrial function in PCOS}

To determine the gene expression profile of skeletal muscle in PCOS, we performed transcriptomic analysis by RNA sequencing (RNA-seq) of skeletal muscle biopsies from women with PCOS and healthy controls. MDS plots of RNA-seq data showed a marked separation by group (PCOS vs controls) and between skeletal muscle and primary myotubes, and did not suggest the presence of outliers

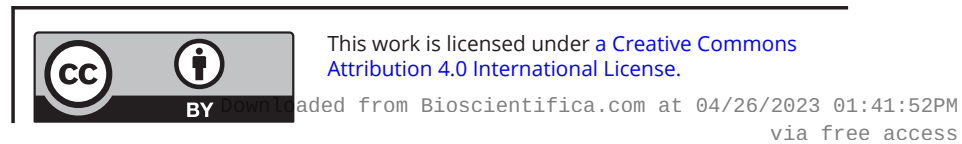


A

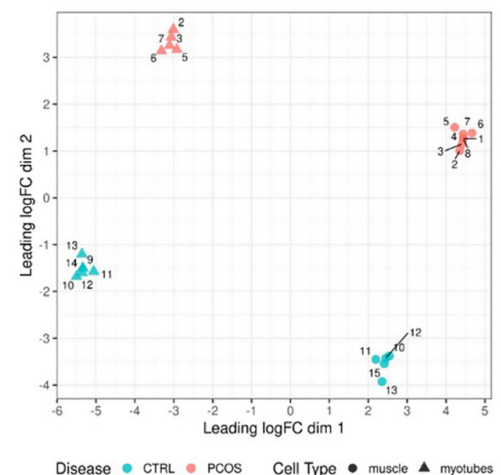

D

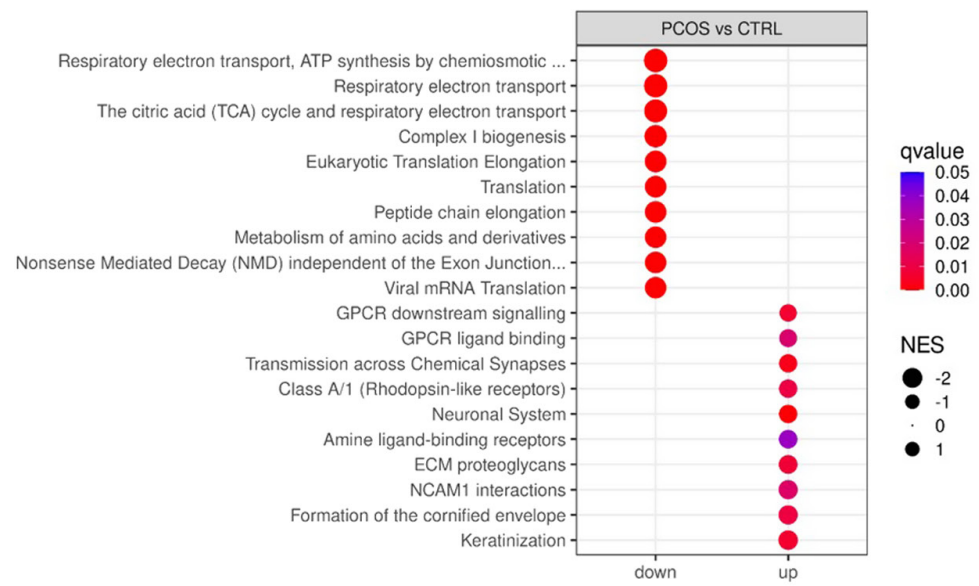

C
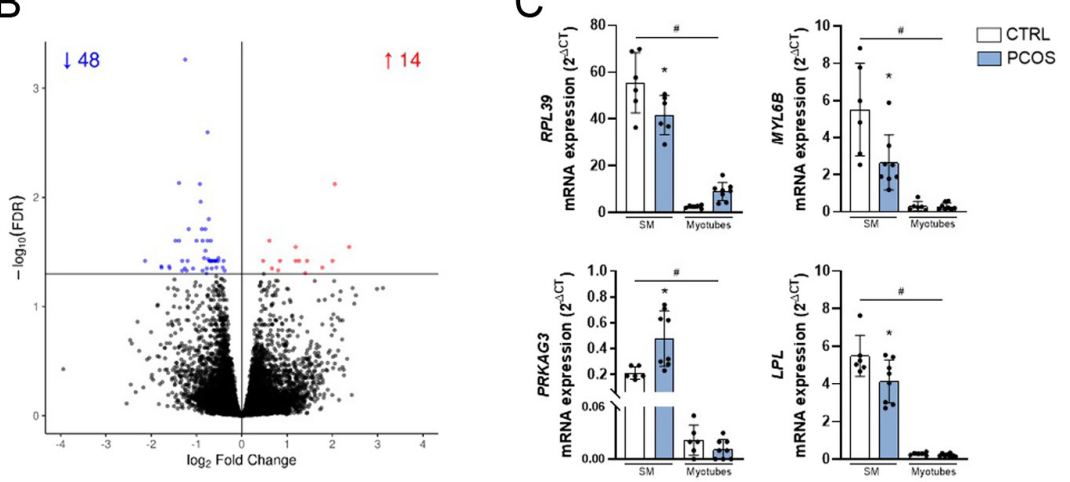

E Pyruvate metabolism and Citric Acid (TCA) cycle LDHB ATP5MC3

Respiratory electron transport, ATP synthesis ATP5F1C ATP5ME ATP5PO NDUFAB1 Mitochondrial translation MRPS22 $\begin{array}{lr}\text { Metabolism of aminoacids and derivatives } & \text { MRPS18B } \\ & \text { BCKDHB } \\ \text { ALDH6A1 } & \text { DHTKD1 } \\ \text { D } \\ \text { AFMID }=\end{array}$

\section{Figure 1}

Gene expression analysis of skeletal muscle. (A) Multidimensional scaling (MDS) plot of RNA-seq data from skeletal muscle (SM) (muscle) and primary myotube cultures (myotubes) from women with PCOS (PCOS) and healthy control women (CTRL). (B) Volcano plot of all transcripts detected between SM of women with PCOS and healthy controls, with significantly upregulated genes (red) and downregulated genes (blue) highlighted. (C) mRNA abundance of selected significantly differentially expressed genes in RNA-seq data from SM and myotubes from healthy controls (CTRL, $n=6$; in white) and PCOS women (PCOS, $n=8$; in blue). Gene expression is expressed as $2-\Delta C \mathrm{~T}$ and represented as mean \pm S.D. ${ }^{*} P_{\text {adj }}<0.05$ vs skeletal muscle from healthy controls; ${ }^{\#} P_{\text {adj }}<0.05$ myotubes vs skeletal muscle of each group, respectively. (D) Top 10 upregulated and downregulated Reactome pathways from GSEA in skeletal muscle ( $q$-value $<0.05$ ). (E) Sankey diagram of Reactome pathways and associated genes from over-representation analysis (ORA) of differentially downregulated genes.

(Fig. 1A). We did not detect any effect of age (Supplementary Fig. 3A), BMI (Supplementary Fig. 3B) or any other confounding clinical variables on the PCOS-specific gene expression profile. In total, we detected a total of 17,690 transcripts, of which 62 genes were differentially expressed (14 upregulated and 48 downregulated; FDR < 0.05) in skeletal muscle of women with PCOS (Fig. $1 \mathrm{~B}$ and Supplementary List 1). Differential expression of a selection of genes RPL39, MYL6B, LPL and PRKAG3 was validated by qRT-PCR (Fig. 1C). GSEA using the Reactome pathway database (Supplementary List 2) showed that genes associated with mitochondrial function and protein translation are specifically downregulated in the skeletal muscle of women with PCOS compared to controls (Fig. 1D). The main mitochondrial functions Printed in Great Britain that were downregulated included the citric acid (TCA) cycle, mitochondrial biogenesis, ATP synthesis, respiratory electron chain, mitochondrial protein import, and mitochondrial protein translation. Conversely, upregulated pathways were related to keratinization, cell adhesion via NCAM1 interactions, neurotransmitters and chemical synapses, extracellular matrix (ECM) proteoglycans, and GPCR signalling (Fig. 1D). Similar over-represented Reactome pathways were obtained for the restricted list of 48 significantly downregulated genes (Supplementary List 3), with a marked over-representation of genes involved in mitochondrial pathways such as pyruvate metabolism and citric acid (TCA) cycle, mitochondrial biogenesis, respiratory electron chain and ATP synthesis, mitochondrial translation, and metabolism 
of amino acids and derivatives (Fig. 1E). Thus, compared to control group, the skeletal muscle of women with PCOS is characterised by lower expression levels of genes involved in several mitochondrial functions and higher expression of transcripts involved in ECM components.

\section{The skeletal muscle gene expression profile in PCOS is lost in cultured myotubes}

We next aimed to determine whether the altered skeletal muscle transcriptomic signature in PCOS is retained in vitro. To address this, we characterised the gene expression profile of primary myotube cultures. Here also, MDS plots of gene expression data show a marked separation between PCOS and controls, as well as between muscle and primary myotubes (Fig. 1A). We investigated the differences in gene expression between PCOS and controls in primary myotube and found no differentially expressed transcripts (FDR > 0.05) (Supplementary List 4). The lack of differential expression was accompanied by no difference in glucose uptake at basal or insulin-stimulated conditions in cultured myotubes from women with PCOS compared to healthy controls (Fig. 2A). While no significant genes were differentially expressed, GSEA of Reactome pathways analysis returned an enrichment of genes related to an upregulation of muscle contraction, ECM organisation and extracellular signalling in PCOS myotubes and
A

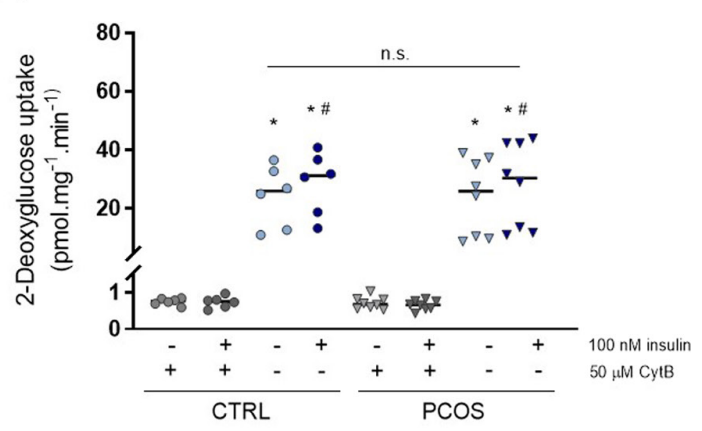

B

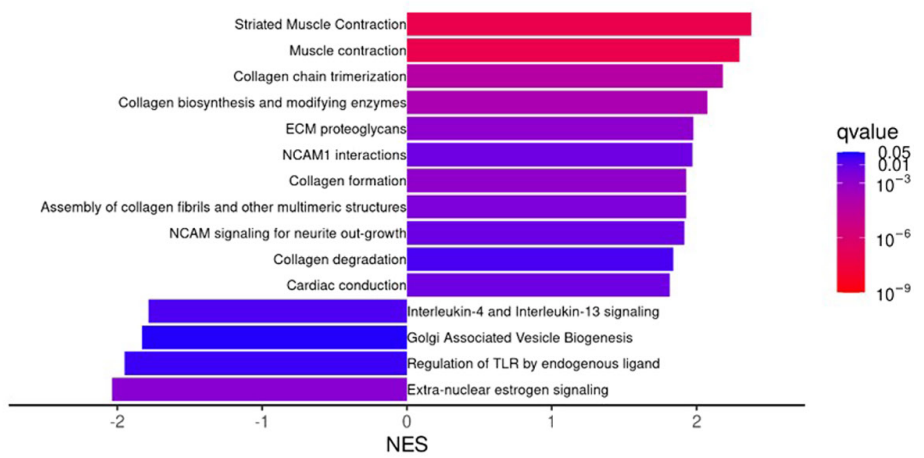

C
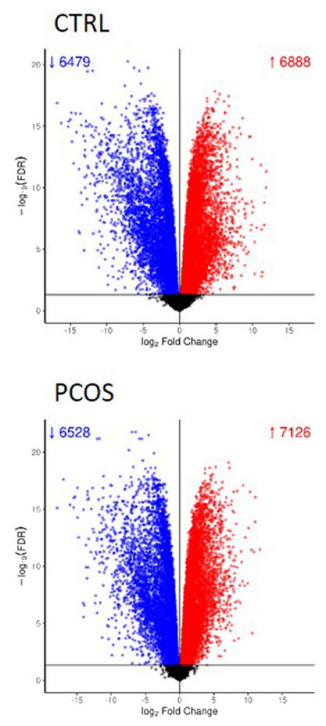

D

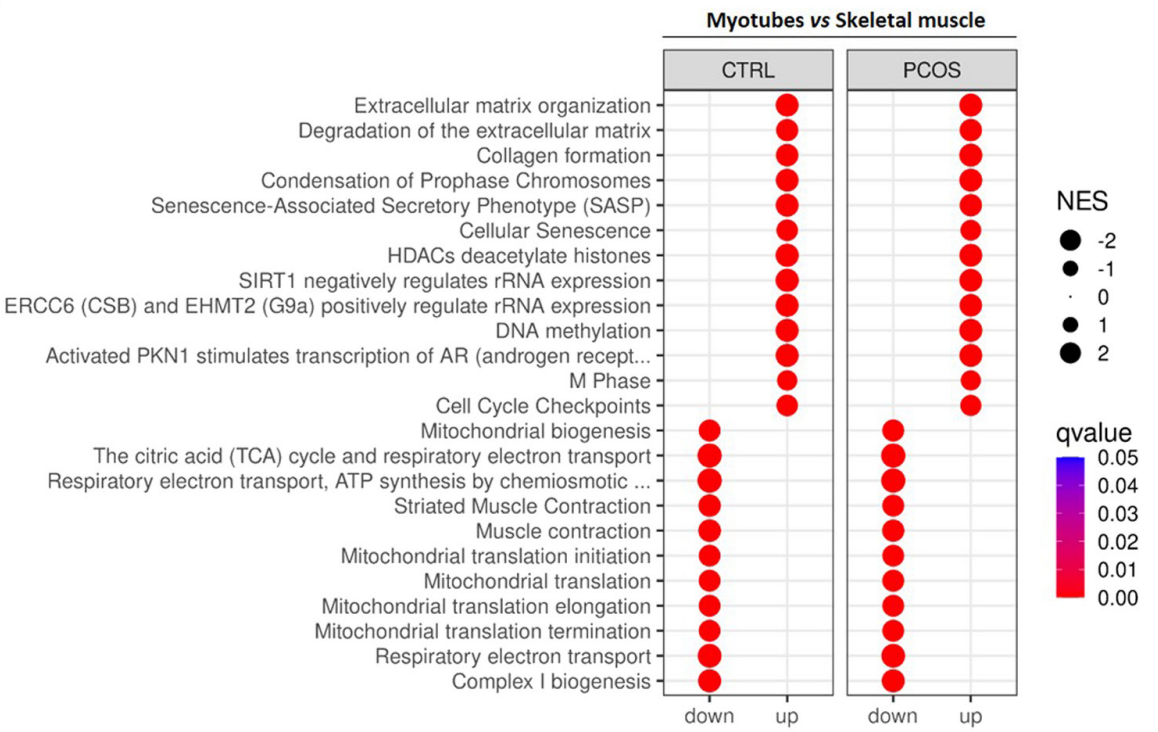

Figure 2

Glucose transport and gene expression analysis of primary myotubes. (A) Glucose uptake of primary myotubes from healthy control women (CTRL, $n=6$ ) and women with PCOS (PCOS, $n=8$ ) showing non-insulin and insulin-stimulated data with and without cytochalasin B (CytB). Line represents the mean value for each group. ${ }^{*} P_{\text {adj }}<0.05$ vs CytB; ${ }^{*} P_{\text {adj }}<0.05$ vs basal (non-insulin stimulated without cytB); n.s. means non-significant difference between PCOS and CTRL. (B) Bar plot of top Reactome pathways from GSEA in myotubes from women with PCOS compared to those from controls ( $q$-value < 0.05 ). (C) Volcano plots of all transcripts detected between myotubes and skeletal muscle from healthy controls (CTRL) or PCOS women (PCOS), with significantly (FDR < 0.05) upregulated genes (red) and downregulated (blue) highlighted. (D) Top 10 upregulated (up) and downregulated (down) Reactome pathways ( $q$-value $<0.05)$ from GSEA in myotubes compared to skeletal muscle for both healthy controls (CTRL) and PCOS women (PCOS), respectively.

https://jme.bioscientifica.com https://doi.org/10.1530/JME-21-0212 (c) 2021 The authors Published by Bioscientifica Ltd. Printed in Great Britain

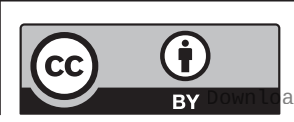

This work is licensed under a Creative Commons Attribution 4.0 International License. ded from Bioscientifica.com at 04/26/2023 01:41:52PM 
lower representation of intracellular processes including signalling regulation and Golgi vesicles biogenesis (Fig. 2B and Supplementary List 5). Thus, our results show that, contrary to skeletal muscle tissue, there is no evident gene expression difference in primary muscle cell cultures from women with PCOS compared to controls, despite a significant enrichment on muscle physiology, ECM components and signalling regulation in the overall gene expression pattern. This suggests that alteration of the skeletal muscle gene expression profile in PCOS may be driven by the extracellular milieu in situ, rather than genetic or epigenetic factors.

\section{Expression of mitochondria-related genes is altered in primary myotubes}

We next compared gene expression between primary myotubes and skeletal muscle and found a total of 13,654 differentially expressed genes in PCOS (7126 upregulated and 6528 downregulated; FDR < 0.05), whereas 13,367 genes (6888 upregulated and 6479 downregulated; FDR < 0.05) were differentially expressed in controls (Fig. 2C and Supplementary List 6). To get functional insight into the difference in gene expression between muscle tissue and cultured primary myotubes, we performed GSEA (Supplementary List 7). From both PCOS and controls, the top downregulated pathways were associated to mitochondria: mitochondrial biogenesis, respiratory electron transport, the citric acid (TCA) cycle, mitochondrial translation, and muscle contraction (Fig. 2D). Contrary, the upregulated genes in both groups were enriched in pathways involved in ECM organisation, chromatin structure, cellular senescence, and transcriptional regulation (Fig. 2D). These findings were strengthened by the cluster analysis, which identifies groups of genes with the same expression pattern. Genes in clusters $\mathrm{C} 0$ and $\mathrm{C} 1$ were downregulated in primary myotubes compared to skeletal muscle in both PCOS and control women (Fig. 3A). These gene clusters were enriched in pathways associated to mitochondria (Fig. 3B), consistent with the findings from the abovementioned GSEA. Conversely, the genes in clusters C5 and C6 had higher expression in myotubes compared to skeletal muscle (Fig. 3A) and were identified to be mainly involved in ECM components and organisation (Fig. 3B). Altogether, these data show that genes involved in mitochondrial function and energy metabolism are altered in primary muscle cell cultures compared to skeletal muscle tissue, supporting that these genes are regulated by extracellular factors in vivo.
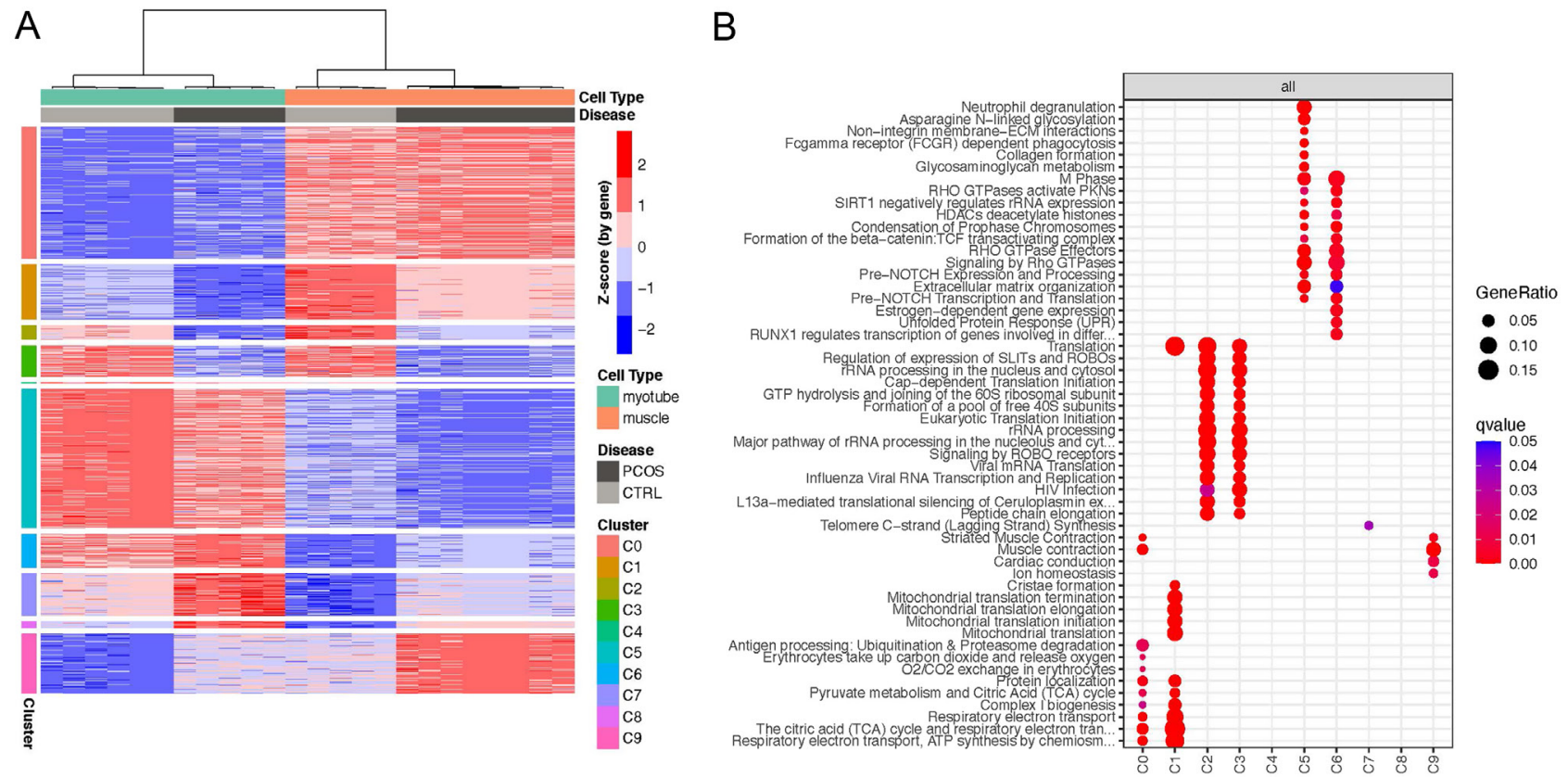

Figure 3

Cluster analysis of gene expression. (A) Heatmap representing cluster analysis results of upregulated (red) and downregulated (blue) genes in myotubes (top green bar) and skeletal muscle (top orange bar) samples from both healthy controls (CTRL; top light grey bar) and PCOS women (PCOS; top dark grey bar). X-axis: Clusters calculated by "clust" algorithm, y-axis: hierarchical clustering of samples using Pearson distance and 'ward.D2' algorithm. (B) Over-representation analysis (ORA) of Reactome pathways ( $q$-value $<0.05)$ for each of the gene clusters.

https://jme.bioscientifica.com https://doi.org/10.1530/JME-21-0212 (c) 2021 The authors Published by Bioscientifica Ltd. Printed in Great Britain

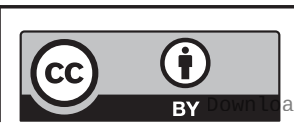

This work is licensed under a Creative Commons Attribution 4.0 International License.

ded from Bioscientifica.com at 04/26/2023 01:41:52PM 
Dysregulation of mitochondria-related genes is observed at the protein level and is independent of mtDNA content

Given the decreased transcript levels of mitochondriarelated genes in skeletal muscle of women with PCOS compared to controls, as well as in primary myotubes regardless of the group, we next sought to investigate the expression levels of mitochondrial-associated proteins. We measured the expression of a selected representative gene and protein from each of the five respiratory complexes (I-V) (NDUFA9, SDHB/SDHA, UQCRC2, COX4a1 and ATP5PD/ATP5A) involved in OXPHOS and two mitochondrial ribosome proteins (MRPS7, MRPL41). Confirming results from the pathway enrichment analysis, qRT-PCR results showed a significant lower expression of
A

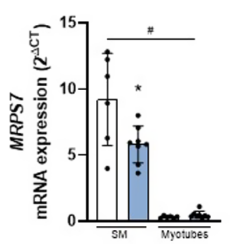

D

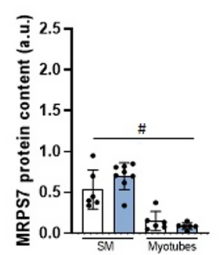

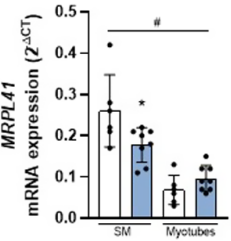

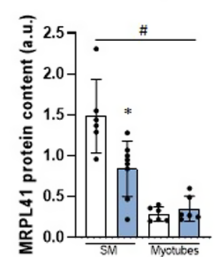

$\square$ CTRL

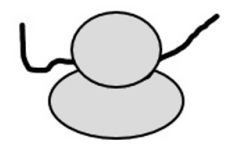

Mitochondrial ribosomes
E

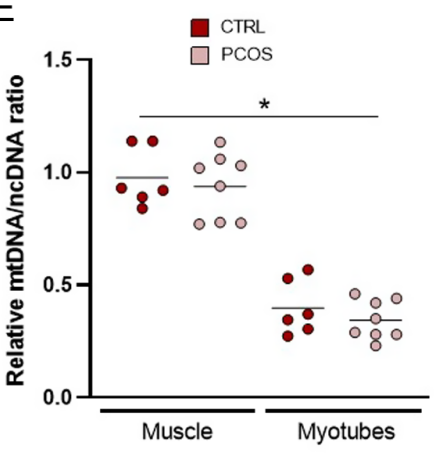

$\mathrm{F}$

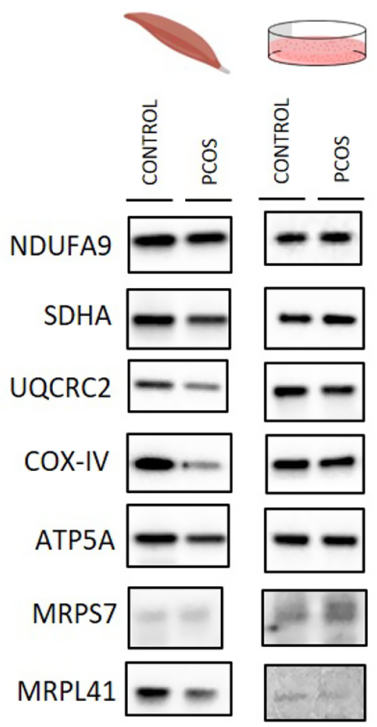

B

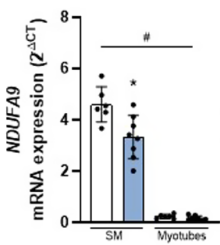

C

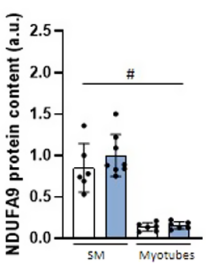

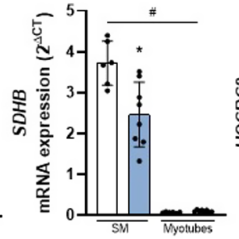
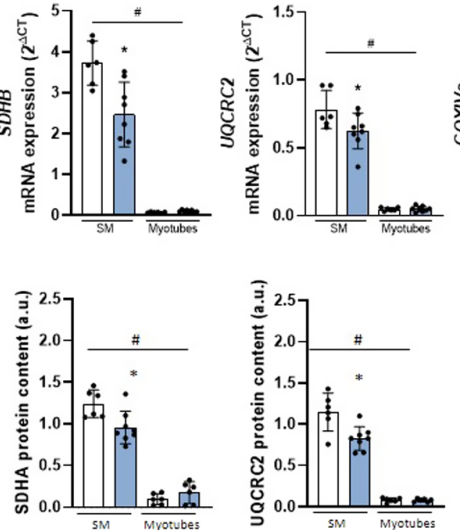

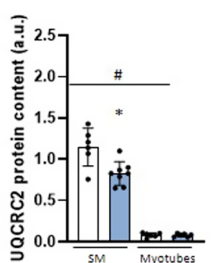

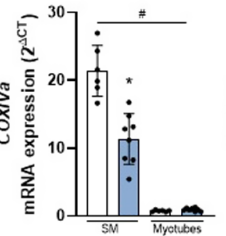

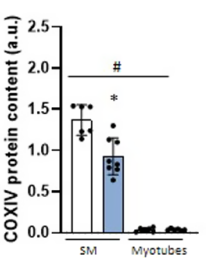

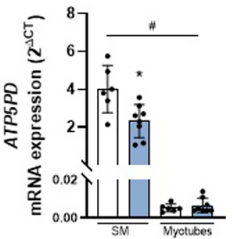

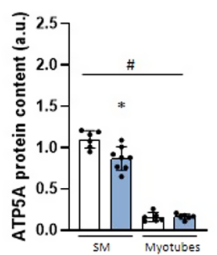

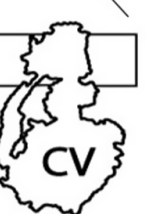

Figure 4

Gene expression and protein abundance of mitochondrial-associated genes and mtDNA copy number in skeletal muscle (SM) and primary myotubes. (A and B) mRNA of mitochondrial OXPHOS complexes I-V (NDUFA9, SDHB, UQCRC2, COX4a1 and ATP5PD) and mitochondrial ribosomes MRPS7 and MRPL41 in SM and primary myotubes. Gene expression is expressed as $2^{-\triangle C T}$ and represented in bar plots showing individual data. (C and D) Protein abundance of mitochondrial OXPHOS complexes I-V (NDUFA9, SDHA, UQCRC2, COX4a1 and ATP5A) and mitochondrial ribosomes MRPS7 and MRPL41 is expressed in arbitrary units (a.u) and represented in bar plots showing individual data. (E) Relative mtDNA/ncDNA ratio expressed as $2-\Delta \Delta C T$ for both SM and myotubes samples from healthy control (CTRL, $n=6)$ and PCOS (PCOS, $n=8)$ women. Line represents the mean value for each group. * $P<0.05$ between SM and myotubes. (F) Representative immunoblots for each of the targets for SM and primary myotubes samples. Healthy controls (CTRL, $n=6$ ) are represented using white bars and women with PCOS (PCOS, $n=8$ ) in blue. Data presented as mean \pm S.D.. ${ }^{*} P_{\text {adj }}<0.05$ vs skeletal muscle from healthy controls; ${ }^{\#} P_{\text {adj }}<0.05$ myotubes vs skeletal muscle.
This work is licensed under a Creative Commons Attribution 4.0 International License. 
the respiratory complexes genes NDUFA9 $(P=0.001), S D H B$ $(P<0.001)$, UQCRC2 $(P=0.024), C O X 4 a 1(P<0.001)$ and $\operatorname{ATP5PD}(P=0.002)$ and the mitochondrial ribosome genes MRPL41 $(P=0.031)$ and MRPS7 $(P=0.008)$ in skeletal muscle of women with PCOS (Fig. 4A, B and Supplementary Fig. 2). We also confirmed a significant lower expression of all these genes in primary myotubes compared to skeletal muscle in both groups $(P<0.001)$ and no differences in primary myotubes between PCOS and controls (Fig. 4A and B).

Protein expression of four out of the five OXPHOS complexes was found to be downregulated in the skeletal muscle of women with PCOS (Fig. 4C). Complex I (NDUFA9) was not significantly decreased $(P=0.32)$, while complex II (SDHA) showed a reduction of 29\% $(P=0.014)$, complex III (UQCRC2) was decreased by 39\% $(P=0.007)$, complex IV (COX4a1) was reduced by $47 \%(P=0.002)$, complex $\mathrm{V}$ (ATP5A) was decreased by $26 \%(P=0.006)$ (Fig. $4 \mathrm{C})$. The mitochondrial ribosome MRPL41 was lower by $76 \%$ $(P=0.01)$, while MRPS7 was not significantly lower $(P=0.15)$ (Fig. 4D). In line with the transcriptomic findings, a marked reduction in mitochondrial ribosomes $(P<0.05)$ and OXPHOS complexes protein content $(P<0.001)$ was detected in primary myotubes compared to skeletal muscle, and no significant differences were observed between myotubes from control and PCOS women (Fig. 4A and B). These results confirm that transcriptomic differences in PCOS skeletal muscle of OXPHOS complexes (II-V) and MRPL41 are translated into differences in protein abundance. Notably, mtDNA content was not distinct between PCOS and healthy control women in skeletal muscle and myotubes. However, there was a significant reduction in mtDNA content in myotubes when compared to skeletal muscle $(P<0.05)$, in accordance with the GSEA data (Fig. 4E). Altogether, our results indicate that lower transcriptomic expression of mitochondria-related genes in skeletal muscle from women with PCOS is associated to a dysregulation at the protein level and is independent of mtDNA content.

\section{Discussion}

Here, we used a transcriptomic approach to investigate the possible contribution of cell-autonomous factors in the gene expression profile of skeletal muscle from women with PCOS. We found that mitochondrial-associated gene pathways represent the main gene expression difference in skeletal muscle of insulin-resistant women with PCOS compared to healthy controls. We show that alteration of mitochondria-related genes is lost in primary muscle cell cultures, indicating that extracellular factors present in the in vivo milieu may be responsible for the gene expression reprogramming of mitochondrial function associated genes in PCOS.

To the best of our knowledge, this study is the first whole-transcriptome analysis performed in skeletal muscle and primary myotubes from women with PCOS. Two studies have previously investigated the skeletal muscle transcriptome in PCOS using array-based gene expression analysis (Skov et al. 2007, Nilsson et al. 2018). One of the studies, which included overweight insulin-resistant women with PCOS and BMI-matched controls, reported a decreased expression in OXPHOS genes in skeletal muscle in PCOS, in accordance with our findings (Skov et al. 2007). Conversely, Nilsson et al. identified 85 differentially expressed transcripts in skeletal muscle from women with PCOS (Nilsson et al. 2018), but contrary to the findings from Skov et al. (2007), none of these genes were differentially expressed in our study nor were they associated with mitochondrial pathways. These discrepancies may be explained by the difference in the metabolic characteristics of the participants as Nilsson et al. did not analyse insulinresistant subjects, with both groups having similar HOMA-IR, HOMA-B or glucose disposal rate (Nilsson et al. 2018). In our study, BMI was not matched between the PCOS and control groups, thus, obesity may represent a confounding factor. However, we did not detect any effect of BMI within groups, suggesting that obesity might not have a major effect on the PCOS-specific gene expression profile in skeletal muscle. It is noteworthy to highlight that despite the limitation of not having BMI- and even agematched participants, our transcriptomic results are similar to those of the aforementioned study which compared overweight/obese insulin-resistant PCOS women with age- and BMI-matched controls (Skov et al. 2007). The dysregulation of genes involved in mitochondrial function is therefore likely to be specific of PCOS insulin resistance itself rather than a characteristic solely driven by obesity. Moreover, a follow-up study further supported the link between dysregulation of mitochondrial-associated genes and insulin resistant in PCOS by showing that pioglitazone treatment improves skeletal muscle insulin sensitivity by upregulation of genes involved in mitochondrial OXPHOS and ribosomal protein biosynthesis in women with PCOS (Skov et al. 2008).

Our study identified transcriptional changes in OXPHOS genes which are accompanied by a substantial decrease of complex II-V proteins, but not complex I. Despite this decreased expression of OXPHOS complexes may suggest that mitochondrial content may be reduced in PCOS women, we did not observe any mtDNA content difference in skeletal muscle of women with PCOS. While

This work is licensed under a Creative Commons Attribution 4.0 International License. ded from Bioscientifica.com at 04/26/2023 01:41:52PM 
we did not assess any other biomarkers of mitochondrial content, our results are consistent with previous studies, which failed to detect mitochondrial content alterations in skeletal muscle from both overweight/obese and lean insulin-resistant women with PCOS (Rabøl et al. 2011, Hutchison et al. 2012, Konopka et al. 2015). However, comprehensive studies using electron microscopy imaging, the gold-standard mitochondrial content marker, as done in obesity and type 2 diabetes (Kelley et al. 2002, Chomentowski et al. 2011), are needed to conclude whether mitochondrial abnormalities in skeletal muscle from PCOS women are due to differences in volume density, morphology or structure.

We detected that pathways associated with ECM organisation, cell adhesion and extracellular signalling molecules were enriched in skeletal muscle from women with PCOS. Dysregulated transforming growth factorbeta (TGFB) signalling and increased production and deposition of collagen has been previously described in the ovaries of women with PCOS (Raja-Khan et al. 2014, Bastian et al. 2016). Deposition of ECM components has been proposed to be involved in the development of PCOS and to contribute to metabolic abnormalities in other tissues (Raja-Khan et al. 2014). In this regard, and in agreement with our observations, a recent study by our group identified altered gene expression of TGFB ligands and components of the ECM, including collagens, in skeletal muscle of insulin-resistant overweight PCOS compared with BMI-matched control women (Stepto et al. 2020). Together, these observations support the existence of a PCOS-specific ECM signature in skeletal muscle and propose a potential role for these extracellular alterations in the metabolic dysfunction of this tissue.

The main objective of our work was to investigate whether the skeletal muscle gene expression signature of insulin-resistant PCOS women is preserved in cultured primary muscle cells. Evidence from other metabolic disorders suggests that primary myotubes derived from women with PCOS may retain the in vivo metabolic characteristics of their donor; however, current studies in PCOS are inconclusive (Corbould et al. 2005, Ciaraldi et al. 2009, Eriksen et al. 2010). In our study, primary myotube cultures established from women with PCOS did not retain insulin resistance, as shown by insulin-stimulated glucose transport, and did not show altered expression of genes related to mitochondrial function. This was also confirmed at protein level for the mitochondrial ribosomes and OXPHOS complexes, with no detectable differences in cultured myotubes from women with PCOS when compared to controls. These results are strengthened by a previous study that also failed to detect any alterations in mitochondrial function or content in myotubes established from insulin-resistant women with PCOS (Eriksen et al. 2011). This loss of in vivo characteristics in primary myotubes suggests that factors present in the extracellular milieu in vivo may be regulating the expression of mitochondrial function associated genes in skeletal muscle of women with PCOS. Remarkably, these findings are in contrast with evidence in type 2 diabetes and obesity, where several defects in insulin signalling, insulin-stimulated glucose metabolism and an impairment of lipid oxidation, ATP synthesis and OXPHOS have been described to be conserved in human primary myotubes (Gaster et al. 2002, Minet \& Gaster 2010, Boyle et al. 2012, Kase et al. 2015). Altogether, our results suggest that the mechanisms responsible for dysregulated skeletal muscle function in PCOS are distinct from those in other metabolic diseases characterized by insulin resistance.

We observed an extensive differential transcriptomic profile between primary myotubes and skeletal muscle, irrespective of the group. We identified in primary myotubes an upregulation of genes related to ECM remodelling, chromatin structure, regulation of protein translation and cellular senescence and a downregulation of genes associated with muscle contraction and multiple mitochondrial functions. Additionally, OXPHOS complex proteins were substantially downregulated in myotubes compared to skeletal muscle tissues, which was accompanied by a significant reduction in mtDNA content. These findings are in line with a previous comparative gene expression profiling study between muscle tissue and myotubes from young healthy females, which showed higher ECM remodelling, cellular senescence and downregulation of genes involved in cellular respiration and OXPHOS in myotubes (Raymond et al. 2010). This metabolic adaptation may be explained by the absence of appropriate extracellular signals in the in vitro settings (Aas et al. 2013), which would lead to reduced mitochondrial content in cultured cells. Therefore, these findings further highlight the contribution of the in vivo extracellular milieu in the regulation of gene and protein expression in skeletal muscle of women with PCOS.

In conclusion, our study identified that pathways controlling mitochondrial function and energy metabolism are lowered in skeletal muscle from insulinresistant women with PCOS, and that these alterations are not preserved in primary myotubes. Our experimental setup comparing transcriptomic profiles of skeletal muscle tissue and derived myotube cultures allowed us to rule out the exclusive contribution of genetic and

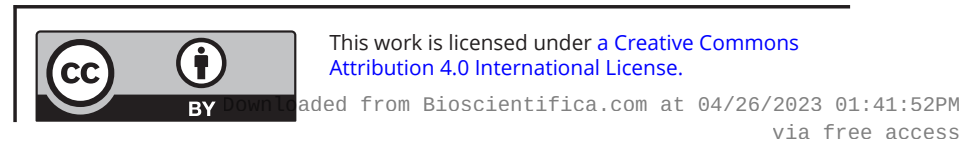


epigenetic factors in the dysregulation of mitochondrialassociated genes described in PCOS. Our findings open an avenue for the discovery of circulating and paracrine factors present in the extracellular milieu, which could represent targets for the treatment of insulin resistance in PCOS

\section{Supplementary materials}

This is linked to the online version of the paper at https://doi.org/10.1530/ JME-21-0212.

\section{Declaration of interest}

The authors declare that there is no conflict of interest that could be perceived as prejudicing the impartiality of the research reported.

\section{Funding}

This work was supported by the National Health and Medical Research Council Centre for Research Excellence in PCOS, Australia, and the Novo Nordisk Foundation Centre for Basic Metabolic Research, an independent research centre at the University of Copenhagen.

\section{Acknowledgements}

The authors acknowledge The Single-Cell Omics platform at the Centre for Basic Metabolic Research (CBMR) for the technical expertise and support, Dr Soulmaz Shorakae for confirming the diagnosis of women with PCOS and Dr Sarah Voisin for her contribution to funding acquisition. The authors also wish to acknowledge the passing of their esteemed colleague and friend Prof Nigel Stepto, who had a vital contribution in the conception, design and data acquisition of this study.

\section{References}

Aas V, Bakke SS, Feng YZ, Kase ET, Jensen J, Bajpeyi S, Thoresen GH \& Rustan AC 2013 Are cultured human myotubes far from home? Cell and Tissue Research 354 671-682. (https://doi.org/10.1007/s00441-0131655-1)

Abu-Jamous B \& Kelly S 2018 Clust: automatic extraction of optima co-expressed gene clusters from gene expression data. Genome Biology 19 172. (https://doi.org/10.1186/s13059-018-1536-8)

Agley CC, Rowlerson AM, Velloso CP, Lazarus NR \& Harridge SDR 2013 Human skeletal muscle fibroblasts, but not myogenic cells, readily undergo adipogenic differentiation. Journal of Cell Science $\mathbf{1 2 6}$ 5610-5625. (https://doi.org/10.1242/jcs.132563)

Bastian NA, Bayne RA, Hummitzsch K, Hatzirodos N, Bonner WM, Hartanti MD, Irving-Rodgers HF, Anderson RA \& Rodgers RJ 2016 Regulation of fibrillins and modulators of TGF $\beta$ in fetal bovine and human ovaries. Reproduction 152 127-137. (https://doi.org/10.1530/ REP-16-0172)

Bergstrom J 1975 Percutaneous needle biopsy of skeletal muscle in physiological and clinical research. Scandinavian Journal of Clinical and Laboratory Investigation 35 609-616. (https://doi. org/10.3109/00365517509095787)

Boyle KE, Zheng D, Anderson EJ, Neufer PD \& Houmard JA 2012 Mitochondrial lipid oxidation is impaired in cultured myotubes from Printed in Great Britain obese humans. International Journal of Obesity 36 1025-1031. (https:// doi.org/10.1038/ijo.2011.201)

Cassar S, Misso ML, Hopkins WG, Shaw CS, Teede HJ \& Stepto NK 2016 Insulin resistance in polycystic ovary syndrome: a systematic review and meta-analysis of euglycaemic-hyperinsulinaemic clamp studies. Human Reproduction 31 2619-2631. (https://doi.org/10.1093/humrep/ dew243)

Chanon S, Durand C, Vieille-Marchiset A, Robert M, Dibner C, Simon C \& Lefai E 2017 Glucose uptake measurement and response to insulin stimulation in in vitro cultured human primary myotubes. Journal of Visualized Experiments 124 55743. (https://doi.org/10.3791/55743)

Chomentowski P, Coen PM, Radiková Z, Goodpaster BH \& Toledo FG 2011 Skeletal muscle mitochondria in insulin resistance: differences in intermyofibrillar versus subsarcolemmal subpopulations and relationship to metabolic flexibility. Journal of Clinical Endocrinology and Metabolism 96 494-503. (https://doi.org/10.1210/jc.2010-0822)

Ciaraldi TP, Aroda V, Mudaliar S, Chang RJ \& Henry RR 2009 Polycystic ovary syndrome is associated with tissue-specific differences in insulin resistance. Journal of Clinical Endocrinology and Metabolism 94 157-163. (https://doi.org/10.1210/jc.2008-1492)

Corbould A 2008 Insulin resistance in skeletal muscle and adipose tissue in polycystic ovary syndrome: are the molecular mechanisms distinct from type 2 diabetes? Panminerva Medica 50 279-294.

Corbould A, Kim YB, Youngren JF, Pender C, Kahn BB, Lee A \& Dunaif A 2005 Insulin resistance in the skeletal muscle of women with PCOS involves intrinsic and acquired defects in insulin signaling. American Journal of Physiology: Endocrinology and Metabolism 288 E1047-E1054. (https://doi.org/10.1152/ajpendo.00361.2004)

DeFronzo RA, Tobin JD \& Andres R 1979 Glucose clamp technique: a method for quantifying insulin secretion and resistance. American Journal of Physiology 237 E214-E223. (https://doi.org/10.1152/ ajpendo.1979.237.3.E214)

DeFronzo RA, Ferrannini E, Sato Y, Felig P \& Wahren J 1981 Synergistic interaction between exercise and insulin on peripheral glucose uptake. Journal of Clinical Investigation 68 1468-1474. (https://doi.org/10.1172/ jci110399)

Dunaif A, Segal KR, Futterweit W \& Dobrjansky A 1989 Profound peripheral insulin resistance, independent of obesity, in polycystic ovary syndrome. Diabetes 38 1165-1174. (https://doi.org/10.2337/ diab.38.9.1165)

Dunaif A, Segal KR, Shelley DR, Green G, Dobrjansky A \& Licholai T 1992 Evidence for distinctive and intrinsic defects in insulin action in polycystic ovary syndrome. Diabetes 41 1257-1266. (https://doi. org/10.2337/diab.41.10.1257)

Dunaif A, Wu X, Lee A \& Diamanti-Kandarakis E 2001 Defects in insulin receptor signaling in vivo in the polycystic ovary syndrome (PCOS) American Journal of Physiology: Endocrinology and Metabolism 281 E392-E399. (https://doi.org/10.1152/ajpendo.2001.281.2.E392)

Ehrmann DA 2005 Polycystic ovary syndrome. New England Journal of Medicine 352 1223-1236. (https://doi.org/10.1056/NEJMra041536)

Eriksen M, Pørneki AD, Skov V, Burns JS, Beck-Nielsen H, Glintborg D \& Gaster M 2010 Insulin resistance is not conserved in myotubes established from women with PCOS. PLoS ONE 5 e14469. (https://doi. org/10.1371/journal.pone.0014469)

Eriksen MB, Minet AD, Glintborg D \& Gaster M 2011 Intact primary mitochondrial function in myotubes established from women with PCOS. Journal of Clinical Endocrinology and Metabolism 96 E1298-E1302. (https://doi.org/10.1210/jc.2011-0278)

Gaster M 2019 The diabetic phenotype is preserved in myotubes established from type 2 diabetic subjects: a critical appraisal. APMIS 127 3-26. (https://doi.org/10.1111/apm.12908)

Gaster M, Petersen I, Højlund K, Poulsen P \& Beck-Nielsen H 2002 The diabetic phenotype is conserved in myotubes established from diabetic subjects: evidence for primary defects in glucose transport and glycogen synthase activity. Diabetes 51 921-927. (https://doi. org/10.2337/diabetes.51.4.921)

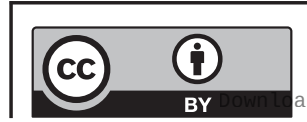

This work is licensed under a Creative Commons Attribution 4.0 International License. 
Hansen SL, Svendsen PF, Jeppesen JF, Hoeg LD, Andersen NR, Kristensen JM, Nilas L, Lundsgaard AM, Wojtaszewski JFP, Madsbad S, et al. 2019 Molecular mechanisms in skeletal muscle underlying insulin resistance in women who are lean with polycystic ovary syndrome. Journal of Clinical Endocrinology and Metabolism 104 1841-1854. (https://doi.org/10.1210/jc.2018-01771)

Hiam D, Simar D, Laker R, Altıntaș A, Gibson-Helm M, Fletcher E, Moreno-Asso A, Trewin AJ, Barres R \& Stepto NK 2019 Epigenetic reprogramming of immune cells in women with PCOS impact genes controlling reproductive function. Journal of Clinical Endocrinology and Metabolism 104 6155-6170. (https://doi.org/10.1210/jc.201901015)

Højlund K, Glintborg D, Andersen NR, Birk JB, Treebak JT, Frøsig C, BeckNielsen H \& Wojtaszewski JF 2008 Impaired insulin-stimulated phosphorylation of Akt and AS160 in skeletal muscle of women with polycystic ovary syndrome is reversed by pioglitazone treatment. Diabetes 57 357-366. (https://doi.org/10.2337/db07-0706)

Hutchison SK, Teede HJ, Rachon D, Harrison CL, Strauss BJ \& Stepto NK 2012 Effect of exercise training on insulin sensitivity, mitochondria and computed tomography muscle attenuation in overweight women with and without polycystic ovary syndrome. Diabetologia $\mathbf{5 5}$ 1424-1434. (https://doi.org/10.1007/s00125-011-2442-8)

Kase ET, Feng YZ, Badin PM, Bakke SS, Laurens C, Coue M, Langin D, Gaster M, Thoresen GH, Rustan AC, et al. 2015 Primary defects in lipolysis and insulin action in skeletal muscle cells from type 2 diabetic individuals. Biochimica et Biophysica Acta 1851 1194-1201. (https://doi.org/10.1016/j.bbalip.2015.03.005)

Kelley DE, He J, Menshikova EV \& Ritov VB 2002 Dysfunction of mitochondria in human skeletal muscle in type 2 diabetes. Diabetes 51 2944-2950. (https://doi.org/10.2337/diabetes.51.10.2944)

Konopka AR, Asante A, Lanza IR, Robinson MM, Johnson ML, Dalla Man C, Cobelli C, Amols MH, Irving BA \& Nair KS 2015 Defects in mitochondrial efficiency and $\mathrm{H} 2 \mathrm{O} 2$ emissions in obese women are restored to a lean phenotype with aerobic exercise training. Diabetes 64 2104-2115. (https://doi.org/10.2337/db14-1701)

Krishnan KJ, Bender A, Taylor RW \& Turnbull DM 2007 A multiplex realtime PCR method to detect and quantify mitochondrial DNA deletions in individual cells. Analytical Biochemistry 370 127-129. (https://doi.org/10.1016/j.ab.2007.06.024)

Minet AD \& Gaster M 2010 ATP synthesis is impaired in isolated mitochondria from myotubes established from type 2 diabetic subjects. Biochemical and Biophysical Research Communications $\mathbf{4 0 2}$ 70-74. (https://doi.org/10.1016/j.bbrc.2010.09.115)

Moghetti P, Tosi F, Bonin C, Di Sarra D, Fiers T, Kaufman JM, Giagulli VA, Signori C, Zambotti F, Dall'Alda M, et al. 2013 Divergences in insulin resistance between the different phenotypes of the polycystic ovary syndrome. Journal of Clinical Endocrinology and Metabolism 98 E628-E637. (https://doi.org/10.1210/jc.2012-3908)

Nana A, Slater GJ, Stewart AD \& Burke LM 2015 Methodology review: using dual-energy X-ray absorptiometry (DXA) for the assessment of body composition in athletes and active people. International Journal of Sport Nutrition and Exercise Metabolism 25 198-215. (https://doi. org/10.1123/ijsnem.2013-0228)

Nilsson E, Benrick A, Kokosar M, Krook A, Lindgren E, Kallman T, Martis MM, Hojlund K, Ling C \& Stener-Victorin E 2018 Transcriptional and epigenetic changes influencing skeletal muscle metabolism in women with polycystic ovary syndrome. Journal of Clinical Endocrinology and Metabolism 103 4465-4477. (https://doi. org/10.1210/jc.2018-00935)
Quiros PM, Goyal A, Jha P \& Auwerx J 2017 Analysis of mtDNA/nDNA ratio in mice. Current Protocols in Mouse Biology 7 47-54. (https://doi. org/10.1002/cpmo.21)

Rabøl R, Svendsen PF, Skovbro M, Boushel R, Schjerling P, Nilas L, Madsbad S \& Dela F 2011 Skeletal muscle mitochondrial function in polycystic ovarian syndrome. European Journal of Endocrinology 165 631-637. (https://doi.org/10.1530/EJE-11-0419)

Raja-Khan N, Urbanek M, Rodgers RJ \& Legro RS 2014 The role of TGFbeta in polycystic ovary syndrome. Reproductive Sciences $\mathbf{2 1} 20-31$. (https://doi.org/10.1177/1933719113485294)

Raymond F, Métairon S, Kussmann M, Colomer J, Nascimento A, Mormeneo E, García-Martínez C \& Gómez-Foix AM 2010 Comparative gene expression profiling between human cultured myotubes and skeletal muscle tissue. BMC Genomics 11 125. (https://doi. org/10.1186/1471-2164-11-125)

Rotterdam ESHRE/ASRM-Sponsored PCOS Consensus Workshop Group 2004 Revised 2003 consensus on diagnostic criteria and long-term health risks related to polycystic ovary syndrome. Fertility and Sterility 81 19-25. (https://doi.org/10.1016/j.fertnstert.2003.10.004)

Shanely RA, Zwetsloot KA, Triplett NT, Meaney MP, Farris GE \& Nieman DC 2014 Human skeletal muscle biopsy procedures using the modified Bergström technique. Journal of Visualized Experiments 91 51812. (https://doi.org/10.3791/51812)

Skov V, Glintborg D, Knudsen S, Jensen T, Kruse TA, Tan Q, Brusgaard K, Beck-Nielsen H \& Højlund K 2007 Reduced expression of nuclearencoded genes involved in mitochondrial oxidative metabolism in skeletal muscle of insulin-resistant women with polycystic ovary syndrome. Diabetes 56 2349-2355. (https://doi.org/10.2337/db07-0275)

Skov V, Glintborg D, Knudsen S, Tan Q, Jensen T, Kruse TA, BeckNielsen H \& Højlund K 2008 Pioglitazone enhances mitochondrial biogenesis and ribosomal protein biosynthesis in skeletal muscle in polycystic ovary syndrome. PLoS ONE 3 e2466. (https://doi. org/10.1371/journal.pone.0002466)

Stepto NK, Cassar S, Joham AE, Hutchison SK, Harrison CL, Goldstein RF \& Teede HJ 2013 Women with polycystic ovary syndrome have intrinsic insulin resistance on euglycaemic-hyperinsulaemic clamp. Human Reproduction 28 777-784. (https://doi.org/10.1093/humrep/des463)

Stepto NK, Moreno-Asso A, Mcllvenna LC, Walters KA \& Rodgers RJ 2019 Molecular mechanisms of insulin resistance in polycystic ovary syndrome: unraveling the conundrum in skeletal muscle? Journal of Clinical Endocrinology and Metabolism 104 5372-5381. (https://doi. org/10.1210/jc.2019-00167)

Stepto NK, Hiam D, Gibson-Helm M, Cassar S, Harrison CL, Hutchison SK, Joham AE, Canny BJ, Moreno-Asso A, Strauss BJ, et al. 2020 Exercise and insulin resistance in PCOS: muscle insulin signalling and fibrosis. Endocrine Connections 9 346-359. (https://doi.org/10.1530/EC-19-0551)

Teede H, Deeks A \& Moran L 2010 Polycystic ovary syndrome: a complex condition with psychological, reproductive and metabolic manifestations that impacts on health across the lifespan. $B M C$ Medicine 8 41. (https://doi.org/10.1186/1741-7015-8-41)

Thingholm TE, Bak S, Beck-Nielsen H, Jensen ON \& Gaster M 2011 Characterization of human myotubes from type 2 diabetic and nondiabetic subjects using complementary quantitative mass spectrometric methods. Molecular and Cellular Proteomics 10 M110.006650. (https://doi.org/10.1074/mcp.M110.006650)

Tosi F, Bonora E \& Moghetti P 2017 Insulin resistance in a large cohort of women with polycystic ovary syndrome: a comparison between euglycaemic-hyperinsulinaemic clamp and surrogate indexes. Human Reproduction 32 2515-2521. (https://doi.org/10.1093/humrep/dex308)

Received in final form 29 October 2021

Accepted 9 November 2021

Accepted Manuscript published online 9 November 2021 https://jme.bioscientifica.com https://doi.org/10.1530/JME-21-0212 (c) 2021 The authors Published by Bioscientifica Ltd. Printed in Great Britain

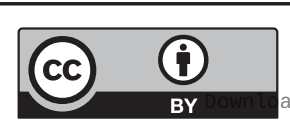

This work is licensed under a Creative Commons Attribution 4.0 International License. ded from Bioscientifica.com at 04/26/2023 01:41:52PM 